\title{
COSTUMER EXPERIENCE, DIFERENSIASI PRODUK, DAN KUALITAS PRODUK TERHADAP KEPUTUSAN PEMBELIAN KONSUMEN DI PUSAT GROSIR SOLO
}

\author{
Yusnia, Burhanuddin \\ Universitas Islam Batik Surakarta \\ Email:yusnia702@gmail.com
}

\begin{abstract}
Pusat Grosir Solo is a modern-based traditional market that has shopping facilities and convenience like most malls This purpose aims to specify customer experience, product differentiation and product quality in the consumer purchasing decisions at Pusat Grosir Solo in Surakarta. This study uses formal distribution and association techniques that aim to describe the relationship between independent and independent variables. The quantity of samples in this learn were 100 respondents who were PGS visitors. The sampling method uses accidental sampling or by chance. The analysis data method make multiple linear regression analysis f test and t test to serve hypothesis outcome represent the variable differentiation and product quality significantly influence consumer purchasing decisions but customer experience has no impact on purchasing decisions
\end{abstract}

Keyword : customer experience, product differentiation and product quality

Abstrak : Pusat grosir solo adalah pasar tradisional berbasis modern yang memiliki faisilitas yang nyaman seperti mall pada umumnya. Tujuan dari penelitian ini yang berjudul Pengalamn pelanggan, Diferensiasi produk dan kualitas produk terhadap keputusan pembelian di pusat grosir solo di Surakarta.Penleitian ini menggunakan teknik data distribusi dan asosiasi yang mendeskripsikan variabel independen dan dependen. Sampel yang diperoleh di percobaan riset ini berjumlah 100 responden yaitu pengunjung yang berada di pUsat grosir solo. Teknik sampling menggunakan accindental sampling yaitu secara kebetulan dan teknik analisis data dengan metode analisis liniear regresi. Hasil penelitian menunjukan bahwa ada satu variabel yang tidak memberikan pengaruh baik secara signifikan dan simultan terhadap keputusan pembelian yaitu variabel costumer experience dan yang berpengaruh variabel diferensiasi produk dan kualitas produk secara signifikan dan simultan terhadap keputusan pembelian konsumen di Pusat Grosir solo

Kata kunci : Pengalaman pelanggan, diferensiasi produk dan kualitas produk

\section{PENDAhuluan}

Zaman milenial ini telah mengantarkan transisi waktu dalam semua kesibukan dan kehidupan human, salah satunya sektor ekonomi yang berdampak pada pertumbuhan ekonomi yang semakin tinggi dalam terjadinya industrialisasi dan peningkatan produktivitas dunia industri. Kemajuan teknologi juga berdampak pada semakin ketatnya persaingan bisnis. Pertarungan yang semakin tidak bisa di pungkiri membuat para pelaku bisnis untuk memastikan program yang bagus dalam kompetensi dengan memenuhi kebutuhan konsumen yang selalu beragam (Putri dkk,2014). Keputusan pembelian yang dilakukan oleh pengunjung sangat 
berpengaruh besar.

Proses konsumen mengenal masalahnya ada di dalam keputusan pembelian. Seorang konsumen akan akan mencoba menggali fakta perihal produk yang dijual dan menilai masingmasing opsi produk dengan tujuan untuk memecahkan masalah serta mengarah pada keputusan pembelian (Paulina,2015). Disetiap sasaran pasar yang dituju, perusahaan dituntut untuk mampu memahami perubahan dan perkembangan pasar serta perilaku pelanggan dengan siasat memenuhi keperluan dan kepentingan pengunjung (An'nisa, 2016). Memahami perilaku konsumen ,diharapkan perusahaan dapat menenangkan pasar dengan menyesuaikan produk yang dihasilkan serta mempertahankan loyalitas konsumen juga perlu diciptakan oleh perusahaan (Rawung, 2015). Apabila konsumen akan memutuskan untuk membeli barang tersebut (Habibah dan Sumiati, 2016

Pengamatan yang dilakukan peneliti pada konsumen di Pusat Grosir Solo Surakarta dalam menentukan keputusan pembelian, melihat pada suatu kondisi produk, variasi produk, sumber informasi yang didapatkan serta kualitas produk yang ada di pusat grosir solo. Pusat grosir solo termasuk pasar lama dikota solo, dimana keberadaanya sudah cukup dikenal di kalangan masyarakat. Berdasarkan dari uraian latar belakang di atas, maka penulis tertarik layak untuk melakukan penelitian dengan judul customer experience, diferensiasi produk, dan kualitas produk terhadap keputusan pembelian konsumen di Pusat Grosir Solo

\section{TELAAH PUSTAKA}

\section{Customer experience}

Pengalaman pelanggan (customer experience) salah satu bagian dalam pemasaran (Marketers Editir,2013) dengan menyediakan customer experience yang berbeda dengan pesaing ,maka dapat menjadi competitive advantage suatu produk atau merek. Customer experience yang berbeda dengan pesaing dapat menarik konsumen baru Jika pelanggan puas dengan pelayanan atau

pengalaman yang didapatkannya ketika menggunakan produk atau jasa, maka kemungkinan besar pelanggan akan melakukan pembelian kembali atau memanfaatkan jasa yang sama secara interatif (Kotler\&Keller ,2012).

\section{Diferensiasi produk}

Diferensiasi produk salah satu aktivitas mentransformasikan produk lama menjadi sebuah produk menarik yang disukai oleh konsumen dimana produk tersebut mengikuti kemajuan zaman milenial. Hal ini memerlukan penyelidikan di pasar secara langsung dengan serius agar bisa menciptakan produk yang berbeda dengan pelaku usaha lainnya. Diferensiasi produk hanya merubah beberapa keunikan produk yaitu pertama kemasan dan tema promosi tanpa mengubah perincian bentuk produk meskipun itu diperlukan sebagai komponen dimana pelaku bisnis berusaha membedakan produk yang satu dengan yang lain. Pelaku bisnis bersaing tanpa 
menurunkan harga. Nilai penting dari diferensiasi produk dengan melakukan transformasi produk, sehingga produk yang dihasilkan berbeda. Sahetapy (2015)

\section{Kualitas produk}

Kualitas produk biasa dijadikan sebagai penyebab adanya kepuasan yang didapat pelanggan sesudah melakukan transaksi atas produk yang dibeli. Pelanggan melakukan re-order atau tidak itu berdasarkan faktor pengalaman yang positif atau negative, maka dari itu pelaku bisnis berupaya membuat sebuah produk yang disesuaikan terhadap kesukaan pembeli. (Rachma, 2014)

\section{Kerangka pemikir teoritis}

Kerangka pemikiran teoritis adalah

$$
\therefore
$$

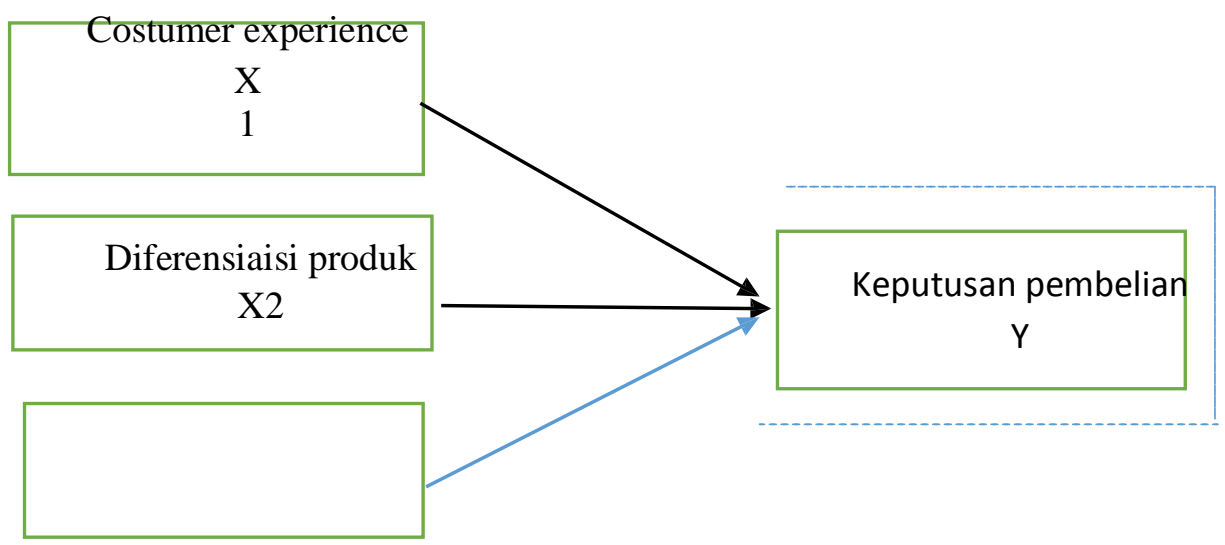




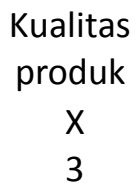

\section{Hipotesis}

Hipotesis yang dihasilkan adalah sebagai berikut :

H1 : Costumer experience memberikan pengaruh signifikan dan positif terhadap keputusan pembelian

H2 : Diferensiasi produk memberikan pengaruh positif dan signifikanterhadap keputusan pembelian

H3 : Kualitas produk memberikan pengaruh positif dan signifikan terhadap keputusan pembelian

\section{METODE PENELITIAN}

a. Jenis dan sumber data

Dalam pengumpulan data diperlukan beberapa jenis data antara lain :

1) Data primer

Data primer yaitu keterangan data yang diperoleh secara langsung dari sumber data pertama dilokasi percobaan riset atau objek penelitian (sugiyono, 2017: 137). Data primer percobaan riset ini adalah hasil kuesioner yang telah dibagikan dan di isi oleh responden pusat grosir solo.

2) Data Sekunder

Data sekuder adalah keterangan yang didapat dari sumber kedua yang dibutuhkan atau sumber sekunder.(Sugiyono, 2017: 137). Data sekunder yang penulis gunakan dalam penelitiuan ini berbentuk jurnal-jurnal yang berhubungan dengan judul customer experience, diferensiasi produk dan kualitas produk terhadap keputusan pembelian; buku-buku yang berhubungan dengan variabel dan perilaku konsumen dan data dari dinas pasar Surakarta

b. Populasi penelitian

Populasi yang diperlukan dalam percobaan riset ini adalah para pengujung di Pusat Grosir solo. Berdasarkan data yang diperoleh pengunjung populasinya 529.320 orang responden dan sampel yang diambil hanya 100 responden saja 


\section{Uji asumsi klasik}

1. Uji normalitas

\begin{tabular}{|l|l|l|}
\hline Unstandarized Residual & \\
\hline$N$ & .100 & Deterangan \\
Kolmograv-smirnov Z & .542 & \\
Asymp.Sig (2 tailed) & .931 & \\
& & \\
\hline
\end{tabular}

Uji normalitas memiliki sebaran data yang normal. Hasil Pengujian Kolmogrov-smirnovTest,nilai p-value $(0.931>0,05)$

2. Uji multikolineritas

\begin{tabular}{lcll}
\hline $\begin{array}{l}\text { Model } \\
\text { Statistics } \\
\text { Keteranagan }\end{array}$ & Colinarity & & \\
\hline & & & \\
\hline & & & \\
\hline Customer experience & 0,784 & 1.275 & Tidak terjadi \\
Diferensiasi produk & 0,711 & 1.407 & $\begin{array}{l}\text { Tidak terjadi } \\
\text { multikolineritas }\end{array}$ \\
Kualitas produk & 0,860 & & $\begin{array}{l}\text { Tidak terjadi } \\
\text { multikolineritas }\end{array}$ \\
\hline
\end{tabular}

Uji multikolineritas menunjukan pada percobaan riset ini model regresi tidak terjadi multikolineritas. Diperoleh dari tolerance value > 0,10 pada VIF kurang dari 10

3. Uji heterokedastisitas

\begin{tabular}{ll}
\hline Model & Sig \\
\hline Customer experience & .144 \\
Diferensiasi produk & .425 \\
Kualitas produk & .060 \\
\hline
\end{tabular}


Independen lebih dari 5\% menunjukan nilai probabilitas yang signifikan dan model regresi tidak terjadi heterokedastisitas hal itu dibuktikan menggunakan uji gletser

Uji regresi liniear

\begin{tabular}{|c|c|c|}
\hline $\boldsymbol{U} \boldsymbol{n}$ & $\begin{array}{l}\text { Coeffcients } \\
\text { error }\end{array}$ & \\
\hline 1 (constatnt) & 3,946 & 2,413 \\
\hline Customer experience & 0,149 & 0,86 \\
\hline Diferensiasi produk & 0,309 & 0,91 \\
\hline Kualitas produk & 0,367 & 0,104 \\
\hline
\end{tabular}

$\mathrm{Y}=3,946+0,149 \mathrm{Xs}+0,309 \mathrm{XL}+0,367 \mathrm{XB}+\mathrm{e}$

Keterangan

1) Nilai konstanta (a) sebesar 3,946 artinya apabila variabel independen (X) adalah 0 (nol)

a. maka variabel dependen (Y) berada di titik 3,946

2) Koefisien variabel customer experience $\left(b^{1}\right)$ dari perhitunagn regresi liniear berganda coefficients $(\mathrm{b})=0,149$. Hal ini menunjukan apabila customer experience naik satuan, sementara variabel diferensiasi produk dan kualitas produk (nol), maka keputusan pembelian akan melonjak dengan nilai 0,149 .

3) variable coefficients diferensiasi (b2) berasal dari kalkulasi regresi liniear berganda dengan nilai coefficients $(\mathrm{b})=0,309$. Hal ini membuktikan bahwa apabila diferensiasi produk naik satu satuan konstan (nol), sementara variabel customer experience dan keputusan pembelian akan melonjak sebesar 0,309

4) variable coefficients kualitas produk (b3) berasal dari perhitungan regresi liniear berganda mempunyai nilai coefficients $(\mathrm{b})=0,367$, hal ini membuktikan bahwa variabel kualitas produk naik satu satuan, sedangkan variabel customer experience dan

a. diferensiasi produk konstan bernilai 0 (nol), sehingga membuat keputusan pembelian bertambah besar dengan nilai 0,367

\section{Uji F}

Uji ini diperlukan sebagai alat untuk mendeskripsikan pengaruh variable independent yaitu Costumer experience, diferensiasi produk dan kualitas produk(X) terhadap variable dependen Keputusan pembelian(Y) produk di Pusat Grosir Solo nilai F hitung adalah sebsar 18.875, dikarenakan Fhitung $>$ f tabel $(18.875>270$ dan signifikan sebesar 0,000 > 0,05 maka H0 di tolak. Dapat disimpulkan Ha diterima sehingga dapat di artikan variable independent (X) memberikan pengaruh yang baik secara simultan dan signifikan terhadap variable dependent di Pusat Grosir Solo 


\section{Uji t}

Seberapa besar pengaruh variabel X terhadap Y maka penulis mengujinya dengan menggunkan uji t sebagai alatnya agar mengetahui hasil yang di inginkan. Hasil analisis data yaitu :

1. Customer experience

Nilai ttabel $<$ thitung $(1,985>1.178)$ nilai signifikan $0,085>0,05$ sehingga $\mathrm{H} 0$ diterima dan H1 ditolak. Sehingga hal itu membuat variabel customer experience memberikan tidak adanya pengaruh secara simultan dan signifikan terhadap keputusan pembelian di Pusat Grosir Solo karena disana orang yang berbelanja kebanyakan para wisatawan dan juga pengunjung yang berkunjung membeli barang ketika dia ada kebutuhan jadi pengalaman pelanggan tidak begitu berpengaruh terhadap keputusan pembelian produk oleh konsumen.

2. Diferensiasi Produk

Nilai ttabel $<$ thitung $(1,985<3.394)$ nilai signifikan $0,001<0,05$ maka H0 ditolak dan H1 diterima. Maka dari itu variabel diferensiasi produk memberikan efek secara positif dan signifikan berpengaruh terhadap keputusan pembelian Pusat Grosir Solo barang yang dijual di pusat grosir solo berbeda dengan yang dijual di pasar lain di PGS menyediakan berbagai macam batik terutam batik printing dan tulis. Saat ini batik printing banyak dicari masyarakat karena model kekinian dan motifnya bagus serta harganya murah juga jadi banyak dicari konsumen

\section{Kualitas Produk}

Nilai ttabel < thitung $(1,985<3.542)$ nilai signifikan 0,001 < 0,05 maka H0 ditolak dan H1 diterima. Maka dari itu variabel kualitas produk berpengaruh secara positif dan signifikan berpengaruh terhadap keputusan pembelian di Pusat Grosir Solo

\section{Uji $\mathbf{R}^{2}$}

Nilai $\mathrm{R}^{2} 35,1 \%$ artinya determanasi atau sumbangan variabel independent terhadap variabel dependent di Pusat Grosir Solo sebesar 35,1\%. Sisanya sebesar 64,9 \%

\section{Pembahasan}

Dari uji F menunjukkan nilai Fhitung > Ftabel $(18.875>2,70)$ dan signifikansi $0,000<$ 0,05. Hasil itu membuktikan bahwa semakin tinggi variable independent maka akan semakin besar pula variable dependent. Hasil penelitian ini sebanding dengan penelitian sebelumnya Ayu Sp, Imam S \& Edy Y (2015).

Customer experience tidak berpengaruh secara parsial terhadap keputusan pembelian di Pusat Grosir Solo, hal ini dibuktikan dengan uji t yang diperoleh dari ttabel > thitung $(1,985>$ 1.178), nilai signifikansi $0,085>0,05$ dan coefficients regresi memiliki nilai negatif 0,149 yang 
artinya variabel tersebut tidak ada pengaruhnya sama keputusan pembelian karena pembeli membeli keutiuhan sesuai kebutuhan. Hasil percobaan riset ini sejalan dengan penelitian sebelumnya (Amin dan Isfiandi 2015)

Diferensiasi produk berpengaruh besar terhadap keputusan pembelian di Pusat Grosir Solo karena Uji t diperoleh ttabel < thitung $(1,985<3,394)$, nilai signifikansi 0,001 < 0,05 dan koefisien regresi meiliki nilai positif sebesar 0,309. (sahetapy,2013). produk yang dijual di tem[pat tersebut sangat inovatif dan berbeda dengan tempat yang lainnya keputusan pembelian di Pusat Grosi Solo. Sejalan dengan pemikiran (sahetapy 2015)

Kualitas produk memberikan pengaruh yang besar secara signifikan terhadap keputusan pembelian di Pusat Grosir Solo yang peroleh pada ttabel < thitung $(1,985<3,542)$, nilai signifikansi $0,001<0,05$ dan coefficients regresi memiliki nilai positif sebesar 0,367. Artinya semakin bagus kualitas produk maka akan semakin banyak permintaan produk, hal ini mempengaruhi keputusan pembelian pada Hasil percobaan riset simetris dengan penelitian (Maneking dan Lumanauw 2016). Pelanggan akan melakukan re-order di Pusat Grosir Solo jika kualitas produk baik.

Faktor hedonisme konsumen yang ingin membeli barang yang memiliki inovasi yang tinggi dan kualitas bagus membuat para pelaku usaha memutar otak agar konsumen tidak lari ke lapak penjual lainnya .sehingga membuat barang sesuai perkembangan zaman dan sesuai permintaan pelanggan

\section{KESIMPULAN}

a. Customer experience, diferensiasi produk, kualitas produk berpengaruh secara simultan dan signifikan pada keputusan pembelian produk di Pusat Grosir Solo karena

b. Secara positif dan signifikan customer experience tidak bepengaruh terhadap keputusan pembelian konsumen di Pusat Grosir Solo disana orang yang berbelanja kebanyakan para wisatawan dan juga pengunjung yang berkunjung membeli barang ketika dia ada kebutuhan jadi pengalaman pelanggan tidak berpengaruh terhadap keputusan pembelian

c. Secara Positif diferensiasi produk berpengaruh terhadap keputusan pembelian di Pusat Grosir Solo Solo karena barang yang dijual di pusat grosir solo berbeda dengan yang dijual di pasar lain di PGS menyediakan berbagai macam batik terutam batik printing dan tulis. Saat ini batik printing banyak dicari masyarakat karena model kekinian dan motifnya bagus serta harganya murah juga jadi banyak dicari konsumen

d. Secara positif serta signifikan kualitas produk berpengaruh pada keputusan pembelian produk di Pusat Grosir Solo konsumen yang membeli produk di Pusat Grosir Solo selain mencari motif dan model terbaru mereka juga mempertimbangkan kualitas produknya karena kebanyakan konsumen mencari produk dengan harga murah, barang bagus dan kualitas produk terjamin dan di Pusat Grosir Solo memiliki produk dengan kualitas tinggi terbukti banyak pelanggan setiap harinya berkunjung di PGS hanya untuk mencari produk dengan kualitas tinggi 


\section{Saran}

a. Hendaknya Pusat Grosir Solo terus menciptakan tempat belanja yang nyaman dan sesuai selera konsumen yang pada akhirnya dapat berpengaruh terhadap penjualan, seperti menambah produk-produk dengan model terbaru dan banyak dicari masyarakat sehingga dapat meningkatkan kepuasan konsumen

b. Penjual yang ada di Pusat Grosir Solo disarankan terus meningkatkan dan mempertahankan citra pesona batik solo sebagai batik yang bagus dan banyak disukai oleh konsumen dimana meningkatkan diferensiasi produk dengan melakukan pembaharuan produk setiap harinya agar masyarakat tidak jenuh harga yang di tawarkan juga cukup terjangkau yang terbukti mampu menjadai patokan konsumen dalam melakukan pembelian.

c. Sebaiknya penjual batik yang ada di Pusat Grosir Solo terus meningkatkan dan mempertahankan citra Pusat Grosir Solo sebagai pasar tradisional berbasis modern yang dimana para mayorita pelaku bisnis batik menjual produk dengan kualitas produk dengan bahan yang bagus sehingga nyaman digunakan oleh pelanggan

\section{DAFTAR PUSTAKA}

Annissa, V. (2016, Agustus). Pengaruh store atmosphere terhadap keputusan pembelian konsumen caffe little wings di bandung 2016. e-procceding of Aplied science,II, 475.

Habibah U, \& Sumiati. 2016. Pengaruh kualitas produk dan harga terhadap keputusan pembelian produk kosmetik wardah di kota bangkalan Madura. Jurnal Ekonomi dan bisnis, 1 (1):31-48

Paulina. (2015) Pengaruh Diferensiasi, Kualitas Produk Dan Ekuitas Merek Terhadap Keputusan Pembelian Coca-Cola Pada Pt. Bangun Wenang Beverges Company Di Manado. ISSN 2303-11 Vol.3 No.3 Sept.2015, Hal.1113-1124

Kotler,Philip \& Gery Armstrong,(2014), Marketing manajemen, $15^{\text {th }}$ Edition New jersey ; pearson pretice Hall, inc

Kotler,Philip \& Gery Armstrong,(2016), Marketing manajemen, 15th Edition New jersey ;pearson pretice Hall,inc

Kotler,Philip \& Kevin Lane Keller ,(2015), Marketing manajemen, 15th Edition New jersey ;pearson pretice Hall,inc 